\title{
Infused autograft lymphocyte to monocyte ratio predicts survival in classical Hodgkin lymphoma
}

This article was published in the following Dove Press journal:

Journal of Blood Medicine

2 February 2015

Number of times this article has been viewed

\author{
Luis F Porrata \\ David J Inwards \\ Stephen MAnsell \\ Ivana $N$ Micallef \\ Patrick B Johnston \\ William J Hogan \\ Svetomir N Markovic \\ Division of Hematology, Department \\ of Medicine, Mayo Clinic, Rochester, \\ MN, USA
}

\begin{abstract}
The infused autograft lymphocyte to monocyte ratio (A-LMR) as a surrogate marker of host immunity (ie, absolute lymphocyte count) and CD14+ HLA-DR ${ }^{\text {low/neg }}$ immunosuppressive monocytes (ie, absolute monocyte count) is a prognostic factor for patients with diffuse large B-cell lymphoma after autologous peripheral hematopoietic stem cell transplantation (APHSCT). Thus, we set out to investigate if A-LMR can also affect survival post-APHSCT in classical Hodgkin lymphoma. From 1994 to 2012, 183 patients with classical Hodgkin lymphoma who underwent APHSCT were studied. The patients were randomly divided into a training $\operatorname{set}(\mathrm{n}=122)$ and a validation set $(n=61)$. The receiver operating characteristic and area under the curve identified an A-LMR $\geq 1$ as the best cut-off value and validated by the $k$-fold cross-validation in the training set. Multivariate analysis showed A-LMR to be an independent prognostic factor for survival in the training set. Patients with an A-LMR $\geq 1.0$ experienced a superior overall survival (OS) versus patients with an A-LMR $<1.0$ (median OS not reached versus 40.4 months, 5-year OS rates of $86 \%$ [95\% CI 72-93] versus 43\% [95\% CI 28-58], $P<0.0001$, respectively) in the training set. In the validation set, an A-LMR $\geq 1$ showed a median OS of not reached versus 41.4 months for an A-LMR <1, 5-year OS rates of 90\% (95\% CI 73-97) versus 48\% (95\% CI 28-68; $P<0.0001)$. A-LMR provides a platform to engineer an autograft versus tumor effect to improve clinical outcomes in patients with classical Hodgkin lymphoma undergoing APHSCT.
\end{abstract}

Keywords: autograft absolute lymphocyte to monocyte count ratio, survival, autologous peripheral hematopoietic stem cell transplantation, classical Hodgkin lymphoma

\section{Introduction}

The infused autograft lymphocyte to monocyte ratio (A-LMR) has recently been reported to be a prognostic factor for survival in patients with diffuse large B-cell lymphoma (DLBCL) post-autologous peripheral hematopoietic stem cell transplantation (APH$\mathrm{SCT}) .{ }^{1}$ We have reported that the infused autograft-absolute lymphocyte count (A-ALC) affects clinical outcomes in lymphoma patients treated with APHSCT. ${ }^{2}$ In DLBCL, ${ }^{3}$ as well as in classical Hodgkin lymphoma (cHL), ${ }^{4}$ gene expression profiling studies have demonstrated that tumor-infiltrating myeloid-derived suppressor cells (MDSCs) predict clinical outcomes. The human monocytic MDSC subset has been characterized as monocytic $\mathrm{CD} 14^{+}$cells with a low level or lack of antigen presenting HLA-DR molecules $\left(\mathrm{CD} 14^{+} \mathrm{HLA}-\mathrm{DR}{ }^{\text {low/neg }}\right.$ cells). ${ }^{5}$ Our group has reported the presence of circulating immunosuppressive CD $14^{+} \mathrm{HLA}-\mathrm{DR}{ }^{\text {low/neg }}$ peripheral blood monocytes in patients with lymphoma. ${ }^{6}$ These circulating CD14 ${ }^{+} \mathrm{HLA}-\mathrm{DR}{ }^{\text {low/neg }}$ monocytes are recruited and transformed into tumor-associated macrophages by the tumor and impacting survival in cancer patients. ${ }^{7}$ Furthermore, monocyte-derived cells may also provide trophic factors
Correspondence: Luis F Porrata Mayo Clinic, 200 First St SW, Rochester, MN 55905, USA

$\mathrm{Tel}+\mathrm{I} 5072843158$

Fax + I 5072664972

Email porrata.luis@mayo.edu 
that directly promote the growth and survival of malignant lymphocytes. ${ }^{8,9}$

Using the autograft-absolute monocyte count (A-AMC) as a surrogate marker for MDSCs, the A-LMR combines biomarkers of host immunity (A-ALC) and tumor immunosuppression (A-AMC). Thus, we studied if A-LMR can also impact clinical outcomes post-APHSCT in a different lymphoma category of cHL in addition to DLBCL.

\section{Materials and methods}

\section{Patient population}

To participate in the study, patients were required to be candidates for APHSCT with the diagnosis of relapsed $\mathrm{cHL}$ and have mobilized enough peripheral blood stem cells to proceed with APHSCT (minimum of $2.0 \times 10^{6} \mathrm{CD} 34$ cells $/ \mathrm{kg}$ ). Patients were excluded if they failed to mobilize stem cells, required bone marrow harvest, were infused with both peripheral blood and bone marrow harvest-derived stem cells, or participated in stem cell transplantation clinical trials. To keep a homogeneous cohort of patients with Hodgkin lymphoma, patients with nodular lymphocyte predominant Hodgkin lymphoma were excluded because they are considered to have a different disease entity. No patients were lost to follow-up. From 1994 to 2012, 183 patients with cHL qualified for the study. All patients gave written informed consent allowing the use of their medical records for medical research. Approval for the retrospective review of these records was obtained from the Mayo Clinic institutional review board and was in accordance with US federal regulations and the Declaration of Helsinki.

\section{End points}

The primary end point of the study was the impact of A-LMR on overall survival (OS), progression-free survival (PFS), lymphoma-specific survival (LSS), and time to progression (TTP) from the time of APHSCT. The infused A-ALC for each apheresed unit collection was calculated as follows: A-ALC $=\%$ collection lymphocytes $\times$ (absolute white blood cell count [WBC] $/ \mathrm{kg}$ ). In similar fashion, the infused A-AMC for each apheresed unit collection was calculated as follows: $\mathrm{A}-\mathrm{AMC}=\%$ collection monocytes $\times$ (absolute white blood cell count $[\mathrm{WBC}] / \mathrm{kg})$. The A-LMR was then calculated by dividing the A-ALC by the A-AMC.

\section{Prognostic factors}

The following prognostic factors were evaluated in the study: International Prognostic Score ${ }^{10}$ at diagnosis: (age [ $>45$ years], absolute lymphocyte count [ALC] $<600$ cells/ $\mu \mathrm{L}$ or $8 \%$ of WBC, albumin $[\geq 4 \mathrm{~g} / \mathrm{dL}]$, hemoglobin $<10.5 \mathrm{~g} / \mathrm{dL}$, male sex, stage $\mathrm{IV}$, and $\mathrm{WBC} \geq 15,000$ cells $/ \mu \mathrm{L}$, disease status prior to APHSCT [complete remission]), A-LMR, and infused CD34+ stem cells dose.

\section{Peripheral blood stem cell (autograft) collections}

The three types of instruments used at our facility during the period examined in this study were the COBE Spectra (Gambro BCT, Lakewood, CO, USA), Baxter Amicus (Baxter Healthcare, Deerfield, IL, USA), and Fenwal CS3000 (Baxter Healthcare). All patients were collected using a single instrument type based on availability of the instrument on the day of collection. Patients received granulocyte colony-stimulating factor (G-CSF) for mobilization at a dose of $10 \mu \mathrm{g} / \mathrm{kg}$ daily for 5-7 consecutive days by subcutaneous injection. Once the peripheral blood CD34+ cell count was $\geq 10$ cells/ $\mu \mathrm{L}$ on G-CSF, patients began daily apheresis until a minimum target of $2.0 \times 10^{6} \mathrm{CD} 34$ cells $/ \mathrm{kg}$ was reached. If at day 4 on G-CSF the peripheral blood CD34 was less than 10 cells/ $\mu \mathrm{L}$, the addition of plerixafor $0.24 \mathrm{mg} / \mathrm{kg}$ was allowed.

\section{Conditioning regimens}

Conditioning regimens were as follows: 169 patients received BEAM, ie, carmustine (Heritage Pharmaceuticals, Edison, NJ, USA) $300 \mathrm{mg} / \mathrm{m}^{2}$ on day -6 , etoposide (APP Pharmaceuticals, Schaumberg, IL, USA) $100 \mathrm{mg} / \mathrm{m}^{2}$ twice daily from days -5 to -2 , cytarabine (Bedford Laboratories, Bedford, OH, USA) $100 \mathrm{mg} / \mathrm{m}^{2}$ twice daily from days -5 to -2 , and melphalan (Bioniche Pharma, Lake Forest, IL, USA) $140 \mathrm{mg} / \mathrm{m}^{2}$ on day -1 , and 14 patients received cyclophosphamide (Baxter Healthcare) 1,500 $\mathrm{mg} / \mathrm{m}^{2}$ on days -6 to -2 , carmustine (Heritage Pharmaceuticals) $300 \mathrm{mg} / \mathrm{m}^{2}$ on day -6 , and etoposide (APP Pharmaceuticals) $100 \mathrm{mg} / \mathrm{m}^{2}$ twice daily on days -6 to -4 .

\section{Response and survival}

Response criteria were based on the guidelines from the International Harmonization Project on Lymphoma. ${ }^{11}$ OS was measured from the date of transplant to the date of death, or last follow-up. PFS was defined as the time from transplant to the time of progression, relapse, death, or last follow-up. LSS was defined as the time from transplant to death as a result of lymphoma. TTP was defined as the time from transplant until lymphoma progression or death as a result of lymphoma. 


\section{Statistical analysis}

To assess the validity of the A-LMR as a prognostic factor for APHSCT, patients with cHL were randomly divided into two groups. Two-thirds were assigned to the training set $(n=122)$ to develop the best cut-off value for A-LMR, and the remaining third were assigned to the validation set $(n=61)$ to assess the prognostic ability of A-LMR. OS, PFS, LSS, and TTP were analyzed using the approach of Kaplan and Meier. ${ }^{12}$ Differences between survival curves were tested for statistical significance using the two-tailed log-rank test. The Cox proportional hazard model ${ }^{13}$ was used for the univariate and multivariate analysis to evaluate the variables under the prognostic factors section to assess their impact on post-APHSCT OS, PFS, LSS, and TTP times. The choice of optimal cut-off for A-LMR to assess survival was based on its utility as a marker for the clinically relevant binary outcome of death/survival using receiver operating characteristic curves (ROC) and the area under the curve (AUC). The binary clinical outcome (death/survival) was established at 5 years post-APHSCT. Patients were classified as "alive/censored" when follow-up time was longer than 5 years and "death" for patients known to have died before this time point. ${ }^{14} \mathrm{~A} \mathrm{k}$-fold cross-validation with $\mathrm{k}$ values of 10 was performed to validate the results of A-LMR. Randomly chosen subsets containing $90 \%$ of the cohort were used for training, and the remaining $10 \%$ were left for testing. The cross-validation process was then repeated ten times. Based on this analysis, a crossvalidation AUC by the ROC was produced, representing the discriminating accuracy of A-LMR for the binary clinical outcome of death/survival.

Chi-squared and Fisher Exact tests were used to determine relationships between categorical variables as appropriate. The Wilcoxon-rank sum test was used to determine associations between continuous variables and categories, and nonparametric tests were used to evaluate associations for continuous variables. All $P$-values represented were twosided and statistical significance was declared at $P<0.05$.

\section{Results}

\section{Patient characteristics}

The median age at the time of transplant for this cohort of 183 patients with cHL was 33 (range 17-71) years. The distribution of additional baseline characteristics for the patients is presented in Table 1 based on the training set and validation set. The median follow-up for the entire cohort was 34.1 (range 1-183.8) months and for the living patients $(\mathrm{n}=132)$ was 46.2 (range 1.5-183.8) months. The day 100 transplant-related mortality for the cohort of patients was $1.6 \%(3 / 183)$. Forty-five patients died due to relapse/ progression of lymphoma. Three patients died of causes unrelated to lymphoma, excluding the three patients who died in the first 100 days post-APHSCT.

\section{Correlation between A-ALC and ALC-I5, A-AMC and AMC-I5, and A-LMR and LMR-I5}

As in our previous publication on DLBCL, we assessed if the infused A-ALC correlated with the absolute lymphocyte count at day 15 (ALC-15) post-APHSCT, infused A-AMC with absolute monocyte count at day 15 (AMC-15) postAPHSCT, and infused A-LMR and lymphocyte to monocyte ratio at day 15 (LMR-15) post-APHSCT. In the training set and validation set, we identified a strong positive correlation between: A-ALC and ALC-15 $(R=0.8, P<0.0001$ in the training set and $R=0.8, P<0.0001$ in the validation set); A-AMC and AMC-15 $(R=0.8, P<0.0001$ in the training set and $R=0.9, P<0.0001$ in the validation set); and A-LMR and LMR-15 ( $R=0.9, P<0.0001$ in the training set and $R=0.9$, $P<0.0001$ in the validation set). We identified no correlation between the infused CD34 and ALC-15 ( $R=0.1, P=0.1$ in the training set and $R=0.1, P=0.3$ in the validation set); CD34 and AMC-15 ( $R=0.05, P=0.6$ in the training set and $R=0.1, P<0.1$ in the validation set); and CD34 and LMR-15 ( $R=0.07, P=0.9$ in the training set and $R=0.2, P<0.1$ in the validation set).

\section{Cut-off values for A-LMR for survival analysis}

ROC curves and AUC were used to determine the optimal cut-off points for A-LMR based on their utility as a marker for the clinical binary outcome of death/survival in the training set. A-LMR $\geq 1$ had an AUC of 0.80 (95\% CI 0.62-0.98) with a sensitivity of $74 \%$ (95\% CI 68-78) and a specificity of 78\% (95\% CI 74-82; $P<0.01$ ). An internal validation of A-LMR performance as markers for the clinical binary outcome of death/survival was performed using k-fold cross-validation with $\mathrm{k}=10$. We obtained an average AUC of 0.80 ( $95 \%$ CI $0.73-0.88$ ) over the ten validation sets for A-LMR with a standard deviation of \pm 0.02 . We report the ROC for the complete dataset used in the 10 -fold procedure by collecting the A-LMR obtained on each fold. For A-LMR, the cross-validation ROC showed an AUC of 0.80 (95\% CI 0.68-0.92). The similar areas under the curves from the empirical ROC and the cross-validation ROC support the use of A-LMR $\geq 1$ as the cut-off value as the marker of the binary clinical outcome of death/survival. 
Table I Baseline characteristics in the training set and validation set

\begin{tabular}{|c|c|c|c|c|c|c|c|}
\hline \multirow[t]{2}{*}{ Variable } & \multicolumn{3}{|l|}{$\begin{array}{l}\text { Training set } \\
n=122\end{array}$} & \multicolumn{3}{|l|}{$\begin{array}{l}\text { Validation set } \\
n=6 I\end{array}$} & \multirow{2}{*}{$\begin{array}{l}P \text {-value difference } \\
\text { between training } \\
\text { and validation sets }\end{array}$} \\
\hline & $\begin{array}{l}A-L M R \geq I \\
(n=73)\end{array}$ & $\begin{array}{l}\text { A-LMR }<1 \\
(n=49)\end{array}$ & $P$-value & $\begin{array}{l}\text { A-LMR } \geq I \\
(n=36)\end{array}$ & $\begin{array}{l}\text { A-LMR }<1 \\
(n=25)\end{array}$ & $P$-value & \\
\hline \multicolumn{8}{|l|}{ At diagnosis } \\
\hline Age, years, median (range) & $30(19-69)$ & $32(17-66)$ & 0.7 & $32(19-60)$ & $34(|8-7|)$ & 0.9 & 0.6 \\
\hline Sex & & & 0.3 & & & 0.3 & 0.4 \\
\hline Male & $32(44 \%)$ & 27 (55\%) & & $18(50 \%)$ & $16(64 \%)$ & & \\
\hline Female & $4 \mathrm{I}(56 \%)$ & $22(45 \%)$ & & $18(31 \%)$ & $9(36 \%)$ & & \\
\hline $\begin{array}{l}\text { Albumin (g/dL), } \\
\text { median (range) }\end{array}$ & $4.1(1.0-4.7)$ & $4.1(2.7-4.7)$ & 0.5 & $4.2(2.6-4.9)$ & $4.2(2.5-4.9)$ & 0.5 & 0.1 \\
\hline ALC $\times 10^{9} / \mathrm{L}$, median (range) & $1.16(0.3-3.4)$ & $1.02(0.06-3.25)$ & 0.06 & $1.09(0.19-2.74)$ & $0.87(0.19-3.76)$ & 0.1 & 0.2 \\
\hline $\begin{array}{l}\text { Hemoglobin }(\mathrm{g} / \mathrm{dL}) \text {, } \\
\text { median (range) }\end{array}$ & $12.1(7.3-16.0)$ & $12(6.9-15.4)$ & 0.5 & I2.I (8.|-|7.2) & $11.9(9.4-15.2)$ & 0.4 & 0.9 \\
\hline Stage & & & 0.8 & & & 0.2 & 0.4 \\
\hline 1 & $0(0 \%)$ & $0(90 \%)$ & & I (3\%) & $0(0 \%)$ & & \\
\hline 2 & $33(46 \%)$ & $21(43 \%)$ & & $13(36 \%)$ & II (44\%) & & \\
\hline 3 & $20(27 \%)$ & $12(24 \%)$ & & $15(42 \%)$ & $5(20 \%)$ & & \\
\hline 4 & $20(27 \%)$ & $16(33 \%)$ & & $7(19 \%)$ & $9(36 \%)$ & & \\
\hline $\begin{array}{l}\mathrm{WBC} \times 10^{9} / \mathrm{L} \\
\text { median (range) }\end{array}$ & $8.4(2.8-20.1)$ & $8.9(1.1-22.8)$ & 0.2 & $7.4(2.0-20.1)$ & $6.7(1.1-20.7)$ & 0.8 & 0.1 \\
\hline \multicolumn{8}{|l|}{ IPS risk factors } \\
\hline Age, years & & & 0.9 & & & 0.8 & 0.9 \\
\hline$>45$ & $17(23 \%)$ & $12(24 \%)$ & & $8(22 \%)$ & $6(24 \%)$ & & \\
\hline$\leq 45$ & $56(77 \%)$ & $37(76 \%)$ & & $28(78 \%)$ & $19(76 \%)$ & & \\
\hline Albumin (g/dL) & & & 0.9 & & & 0.4 & 0.5 \\
\hline$>1$ & $4 \mathrm{I}(59 \%)$ & 27 (59\%) & & 24 (69\%) & 14 (48\%) & & \\
\hline$\leq 1$ & $29(41 \%)$ & $19(41 \%)$ & & II (3I\%) & $10(42 \%)$ & & \\
\hline ALC-DX $\times 10^{9} / \mathrm{L}$ & & & 0.3 & & & 0.7 & 0.1 \\
\hline$\geq 0.6$ & 47 (64\%) & $26(53 \%)$ & & $21(58 \%)$ & $8(32 \%)$ & & \\
\hline$<0.6$ & $26(36 \%)$ & $23(47 \%)$ & & $15(42 \%)$ & $17(68 \%)$ & & \\
\hline Hemoglobin (g/dL) & & & $<0.02$ & & & 0.4 & 0.9 \\
\hline$>10.5$ & $62(84 \%)$ & 31 (65\%) & & $26(74 \%)$ & $22(85 \%)$ & & \\
\hline$\leq 10.5$ & $12(16 \%)$ & $17(35 \%)$ & & $9(26 \%)$ & $4(15 \%)$ & & \\
\hline Stage 4 & & & 0.5 & & & 0.2 & 0.7 \\
\hline Yes & $20(27 \%)$ & $16(33 \%)$ & & 7 (8I\%) & $9(36 \%)$ & & \\
\hline No & $53(73 \%)$ & $33(67 \%)$ & & $29(19 \%)$ & $16(64 \%)$ & & \\
\hline $\mathrm{WBC} \times 10^{9} / \mathrm{L}$ & & & 0.4 & & & 0.7 & 0.9 \\
\hline$<15$ & $10(8 \%)$ & $5(10 \%)$ & & $5(14 \%)$ & $2(8 \%)$ & & \\
\hline$\leq 15$ & $63(92 \%)$ & $44(90 \%)$ & & $30(86 \%)$ & $23(92 \%)$ & & \\
\hline Number of IPS factors & & & 0.3 & & & 0.09 & 0.4 \\
\hline 0 & II (I5\%) & $3(6 \%)$ & & $5(\mid 4 \%)$ & $3(125)$ & & \\
\hline I & $29(40 \%)$ & $15(31 \%)$ & & $15(42 \%)$ & $4(16 \%)$ & & \\
\hline 2 & $14(19 \%)$ & $13(26 \%)$ & & $8(22 \%)$ & $9(36 \%)$ & & \\
\hline 3 & $14(19 \%)$ & $14(29 \%)$ & & $6(16 \%)$ & $3(12 \%)$ & & \\
\hline 4 & $4(6 \%)$ & $2(4 \%)$ & & I (3\%) & $4(16 \%)$ & & \\
\hline 5 & I (I\%) & $2(4 \%)$ & & $0(0 \%)$ & $2(8 \%)$ & & \\
\hline 6 & $0(0 \%)$ & $0(0 \%)$ & & I (3\%) & $0(0 \%)$ & & \\
\hline IPS index & & & 0.2 & & & 0.3 & 0.7 \\
\hline$\geq 3$ & $19(26 \%)$ & $18(37 \%)$ & & $8(22 \%)$ & $9(36 \%)$ & & \\
\hline$<3$ & $54(74 \%)$ & $31(63 \%)$ & & $28(78 \%)$ & $16(64 \%)$ & & \\
\hline Initial chemotherapy & & & 0.5 & & & 0.5 & 0.6 \\
\hline ABVD & 7I (98\%) & 49 (100\%) & & $36(100 \%)$ & 24 (96\%) & & \\
\hline Stanford V & I (I\%) & $0(0 \%)$ & & $0(0 \%)$ & I (4\%) & & \\
\hline MOPP & $\mathrm{I}(1 \%)$ & $0(\%)$ & & $0(0 \%)$ & $0(0 \%)$ & & \\
\hline Salvage chemotherapy & & & 0.8 & & & 0.4 & 0.6 \\
\hline ICE & $50(69 \%)$ & 32 (65\%) & & $26(72 \%)$ & 17 (68\%) & & \\
\hline
\end{tabular}


Table I (Continued)

\begin{tabular}{|c|c|c|c|c|c|c|c|}
\hline \multirow[t]{2}{*}{ Variable } & \multicolumn{3}{|l|}{$\begin{array}{l}\text { Training set } \\
n=122\end{array}$} & \multicolumn{3}{|l|}{$\begin{array}{l}\text { Validation set } \\
n=61\end{array}$} & \multirow{2}{*}{$\begin{array}{l}P \text {-value difference } \\
\text { between training } \\
\text { and validation sets }\end{array}$} \\
\hline & $\begin{array}{l}\text { A-LMR } \geq 1 \\
(n=73)\end{array}$ & $\begin{array}{l}\text { A-LMR }<\text { I } \\
(n=49)\end{array}$ & $P$-value & $\begin{array}{l}\text { A-LMR } \geq 1 \\
(n=36)\end{array}$ & $\begin{array}{l}\text { A-LMR }<1 \\
(n=25)\end{array}$ & $P$-value & \\
\hline DHAP & $18(25 \%)$ & $15(31 \%)$ & & $9(25 \%)$ & $5(20 \%)$ & & \\
\hline MOPP & $\mathrm{I}(\mathrm{I} \%)$ & I $(2 \%)$ & & I (2\%) & $2(8 \%)$ & & \\
\hline $\mathrm{EPOCH}$ & I (I\%) & $0(0 \%)$ & & $0(0 \%)$ & $0(0 \%)$ & & \\
\hline ESHAP & $2(3 \%)$ & I (2\%) & & $0(0 \%)$ & I (4\%) & & \\
\hline GVD & I (I\%) & $0(0 \%)$ & & $0(0 \%)$ & $0(0 \%)$ & & \\
\hline \multicolumn{8}{|l|}{ At transplant } \\
\hline $\begin{array}{l}\text { Clinical status pre- } \\
\text { transplant }\end{array}$ & & & 0.4 & & & 0.3 & 0.6 \\
\hline Complete response & $20(27 \%)$ & $8(16 \%)$ & & 17 (47\%) & 7 (28\%) & & \\
\hline Partial response & $39(53 \%)$ & 30 (61\%) & & $12(33 \%)$ & 13 (52\%) & & \\
\hline Refractory & 14 (20\%) & II (23\%) & & 7 (20\%) & $5(20 \%)$ & & \\
\hline Plerixafor & & & 0.2 & & & 0.7 & 0.4 \\
\hline Yes & 18 (25\%) & 7 (14\%) & & $6(17 \%)$ & $3(12 \%)$ & & \\
\hline No & 55 (75\%) & 42 (86\%) & & 30 (83\%) & 22 (88\%) & & \\
\hline Conditioning regimens & & & 0.1 & & & 0.1 & 0.9 \\
\hline CBV & $3(4 \%)$ & $6(12 \%)$ & & I (3\%) & $4(16 \%)$ & & \\
\hline BEAM & 70 (96\%) & 43 (88\%) & & 35 (97\%) & 21 (84\%) & & \\
\hline $\begin{array}{l}\text { Infused CD34, } \\
\text { median (range) }\end{array}$ & $5.3(2.0-14.5)$ & $5.2(2.0-16.1)$ & 0.5 & $5.5(2.9-10.1)$ & $4.9(2.0-11.3)$ & 0.1 & 0.7 \\
\hline A-ALC, median (range) & $0.78(0.21-2.18)$ & $0.39(0.03-1.42)$ & $<0.0001$ & $0.80(0.32-2.6 \mathrm{I})$ & $0.39(0.04-2.01)$ & $<0.0001$ & 0.8 \\
\hline A-AMC, median (range) & $0.47(0.01-1.38)$ & $0.76(0.14-1.97)$ & $<0.0001$ & $0.49(0.11-1.90)$ & $0.75(0.24-2.4 I)$ & $<0.0001$ & 0.1 \\
\hline ALC-I5, median (range) & $0.96(0.16-3.19)$ & $0.48(0.01-2.35)$ & $<0.000$ I & $0.95(0.34-4.12)$ & $0.48(0.29-1.83)$ & $<0.0001$ & 0.8 \\
\hline AMC-I5, median (range) & $0.34(0.05-1.4)$ & $0.74(0.04-7.47)$ & $<0.0001$ & $0.6(0.02-1.77)$ & $0.8(0.05-2.29)$ & $<0.001$ & 0.2 \\
\hline LMR-I5 & $1.7(0.91-16)$ & $0.64(0.79-4.16)$ & $<0.0001$ & I.57 (0.82-3.7) & $0.77(0.27-9)$ & $<0.0001$ & 0.8 \\
\hline
\end{tabular}

Abbreviations: A-ALC, autograft absolute lymphocyte count; A-AMC, autograft absolute monocyte count; ABVD, adriamycin, bleomycin, vinblastine, and dacarbazine; ALC, absolute lymphocyte count; ALC-15, absolute lymphocyte count at day 15 post-transplantation; ALC-DX, absolute lymphocyte count at diagnosis; A-LMR, autograft lymphocyte/monocyte ratio; AMC-I5, absolute monocyte count at day 15 post-transplantation; BEAM, carmustine, etoposide, cytarabine, and melphalan; CBV, cyclophosphamide, carmustine, and etoposide; DHAP, dexamethasone, cytarabine, and cisplatin; EPOCH, etoposide, prednisone, vincristine, cyclophosphamide, and adriamycin; ESHAP, etoposide, methylprednisolone, cytarabine, and cisplatin; GVD, Gemzar ${ }^{\circledast}$, vinorelbine, and liposomal doxorubicin; ICE, ifosfamide, carboplatin, and etoposide; IPS, International Prognostic Score; LMR-15, lymphocyte to monocyte ratio at day 15 post-transplantation; MOPP, mechlorethamine, vincristine, procarbazine, and prednisone; WBC, white blood cell count.

\section{Predictors for OS, PFS, LSS, and TTP in the training set}

Using the univariate Cox regression analysis, the following variables were predictors for OS and PFS: albumin, ALCDX (diagnosis), hemoglobin, International Prognostic Score, complete response prior to APHSCT, and A-LMR (Table 2). For LSS and TTP, the following variables were predictors: albumin, ALC-DX, International Prognostic Score, complete response prior to APHSCT, and A-LMR (Table 2). Multivariate analysis identified albumin and A-LMR as predictors for OS, PFS, LSS, and TTP (Table 3).

\section{Survival outcomes based on A-LMR}

Using the cut-off value of 1.0 for the A-LMR obtained from the empiric ROC and subsequently validated by k-fold cross-validation in the training set, we tested A-LMR $\geq 1$ for OS, PFS, LSS, and TTP. We observed that patients infused with an A-LMR $\geq 1$ compared with patients infused with an A-LMR $<1$ experienced superior OS (Figure 1A), PFS (Figure 1B), LSS (Figure 1C), and TTP (Figure 1D) in the training set (median OS not reached versus 40.4 months, 5 -year OS rates of $86 \%$ [ $95 \%$ CI $72-93$ ] versus $43 \%$ [ $95 \%$ CI 28-58]), respectively, $P<0.0001$; median PFS not reached versus 8.4 months, 5-year PFS rates of $77 \%$ [95\% CI 64-86] versus 20\% [95\% CI 10-35], respectively, $P<0.0001$; median LSS not reached versus 40.4 months, 5 -year LSS rates of $94 \%$ [95\% CI 83-98] versus $42 \%$ [95\% CI 28-58], respectively, $P<0.0001$; and median TTP not reached versus 8.4 months, 5 -year TTP rates of $86 \%$ [95\% CI 74-93] versus $21 \%$ [95\% CI 11-37], respectively, $P<0.0001$ ). The superior OS, PFS, LSS, and TTP observed in the training set with an A-LMR $\geq 1$ versus the group with an A-LMR $<1$ were further validated in the validation set (median OS [Figure 1E] not reached versus 41.4 months, 5-year OS rates of 90\% [95\% CI 73-97] versus $48 \%$ [95\% CI 73-97], respectively, $P<0.0001$; median 
Table 2 Univariate analysis for overall survival, progression-free survival, lymphoma-specific survival, and time to progression in the training set

\begin{tabular}{|c|c|c|c|c|c|c|c|c|}
\hline \multirow[t]{2}{*}{ Variable } & \multicolumn{2}{|l|}{ OS } & \multicolumn{2}{|l|}{ PFS } & \multicolumn{2}{|l|}{ LSS } & \multicolumn{2}{|l|}{ TTP } \\
\hline & HR (95\% Cl) & $P$-value & HR (95\% Cl) & $P$-value & HR (95\% Cl) & $P$-value & HR (95\% Cl) & $P$-value \\
\hline Age $>45$ years & I.I $25(0.5|5-2.8| 2)$ & 0.8 & I.348 (0.705-2.845) & 0.4 & I.I $20(0.483-3.043)$ & 0.7 & $1.697(0.806-4.157)$ & 0.2 \\
\hline $\begin{array}{l}\text { ALC-DX } \\
\geq 600 \text { cells } / \mu \mathrm{L}\end{array}$ & $0.372(0.180-0.742)$ & $<0.005$ & $0.587(0.339-0.917)$ & $<0.04$ & $0.330(0.146-0.702)$ & $<0.004$ & $0.610(0.336-0.807)$ & $<0.04$ \\
\hline Albumin $\geq 4 \mathrm{~g} / \mathrm{dL}$ & $0.235(0.100-0.509)$ & $<0.0002$ & $0.515(0.290-0.904)$ & $<0.02$ & $0.260(0.101-0.598)$ & $<0.001$ & $0.505(0.269-0.934)$ & $<0.03$ \\
\hline $\begin{array}{l}\text { Hemoglobin } \\
<10.5 \text { g/dL }\end{array}$ & $2.312(1.072-4.7 \mid 2)$ & $<0.03$ & $2.113(1.151-3.736)$ & $<0.02$ & $2.058(0.884-4.437)$ & 0.1 & $1.910(0.283-1.019)$ & 0.06 \\
\hline Male & I.34I (0.674-2.704) & 0.4 & I.34I (0.674-2.704) & 0.4 & I.I54 (0.545-2.44I) & 0.7 & $1.210(0.668-2.20 \mathrm{I})$ & 0.5 \\
\hline$W B C>15 \times 10^{9} / L$ & $1.048(0.440-3.091)$ & 0.9 & $1.550(0.733-2.973)$ & 0.2 & $\mathrm{I} .092(0.42 \mathrm{I}-3.72 \mathrm{I})$ & 0.7 & $1.513(0.652-3.096)$ & 0.3 \\
\hline Stage IV & I.I2I (0.525-2.667) & 0.8 & $1.353(0.727-2.410)$ & 0.3 & I.I3I (0.504-2.876) & 0.8 & $\mathrm{I} .478(0.770-2.72 \mathrm{I})$ & 0.2 \\
\hline IPS $\geq 3$ & $2.224(1.104-4.418)$ & $<0.02$ & 1.597 (I.108-2.77I) & $<0.03$ & $1.973(1.114-4.156)$ & $<0.04$ & $1.293(1.075-2.375)$ & $<0.04$ \\
\hline $\begin{array}{l}\text { CR prior to } \\
\text { APHSCT }\end{array}$ & $0.239(0.039-0.791)$ & $<0.01$ & $0.430(0.165-0.932)$ & $<0.03$ & $0.133(0.010-0.622)$ & $<0.006$ & $0.4 \mathrm{II}(0.142-0.95 \mathrm{I})$ & $<0.04$ \\
\hline$A-L M R \geq I$ & $0.145(0.058-0.318)$ & $<0.0001$ & $0.177(0.094-0.319)$ & $<0.0001$ & $0.065(0.015-0.186)$ & $<0.0001$ & $0.119(0.053-0.238)$ & $<0.0001$ \\
\hline Infused CD34 & $1.009(0.883-1.138)$ & 0.9 & $1.039(0.936-1.145)$ & 0.5 & $1.046(0.914-1.181)$ & 0.5 & 1.067 (0.958-I.I77) & 0.2 \\
\hline
\end{tabular}

Abbreviations: ALC-DX, absolute lymphocyte count at diagnosis; A-LMR, autograft lymphocyte/monocyte ratio; APHSCT, autologous peripheral hematopoietic stem cell transplantation; Cl, confidence interval; CR, complete response; HR, hazard ratio; IPS, International Prognostic Score; LSS, lymphoma-specific survival; OS, overall survival; PFS, progression-free survival; TTP, time to progression; WBC, white blood cell count.

PFS [Figure 1F] not reached versus 9.8 months, 5-year PFS rates of $75 \%$ [95\% CI $57-87]$ versus $22 \%$ [95\% CI 10-44], respectively, $P<0.0001$; median LSS [Figure $1 \mathrm{G}]$ not reached versus 41.8 months, 5-year LSS rates of 90\% [95\% CI 73-97] versus 50\% [95\% CI 30\%-70\%], respectively, $P<0.0001$; and median TTP [Figure 1H] not reached versus 10.5 months, 5 -year TTP rates of $75 \%$ [ $95 \%$ CI $57-87$ ] versus $24 \%$ [ $95 \%$ CI 11-45], respectively, $P<0.0001)$.

\section{Discussion}

In DLBCL, the A-LMR was recently reported to be a predictor for clinical outcomes in patients treated with APHSCT. ${ }^{1}$ Thus, we set out to investigate if the A-LMR can also affect clinical outcomes in a different category and biological type of lymphoma, (cHL), undergoing APHSCT.
Patients with a cHL and an A-LMR $\geq 1$ showed superior OS, PFS, LFS, and TTP versus those with an A-LMR $<1$. In the training set, multivariate analysis revealed that A-LMR was an independent predictor for survival post-APHSCT in cHL patients. A validation set confirmed the findings observed in the training set.

We previously reported ALC-15 to be a prognostic factor for survival in cHL patients undergoing APHSCT. ${ }^{15}$ We subsequently reported that ALC-15 recovery depended directly on the infused A-ALC, suggesting that the collected and infused immune effector cells affected clinical outcomes post-APHSCT. In this study, we confirmed again that ALC-15 correlated with the infused A-ALC, AMC-15 correlated with the infused A-AMC, and LMR15 correlated with the infused A-LMR. No correlation was

Table 3 Multivariate analysis for overall survival, progression-free survival, lymphoma-specific survival, and time to progression in the training set

\begin{tabular}{|c|c|c|c|c|c|c|c|c|}
\hline \multirow[t]{2}{*}{ Variable } & \multicolumn{2}{|l|}{ OS } & \multicolumn{2}{|l|}{ PFS } & \multicolumn{2}{|l|}{ LSS } & \multicolumn{2}{|l|}{ TTP } \\
\hline & HR (95\% Cl) & $P$-value & HR (95\% Cl) & $P$-value & HR (95\% Cl) & $P$-value & HR (95\% Cl) & $P$-value \\
\hline Albumin $\geq 4 \mathrm{~g} / \mathrm{dL}$ & $0.179(0.065-0.445)$ & $<0.0002$ & $0.415(0.218-0.774)$ & $<0.006$ & $0.205(0.07 I-0.527)$ & $<0.0008$ & $0.362(0.182-0.709)$ & $<0.003$ \\
\hline $\begin{array}{l}\text { ALC-DX } \\
\geq 600 \text { cells } / \mu \mathrm{L}\end{array}$ & $0.516(0.235-1.090)$ & 0.08 & $0.730(0.400-1.335)$ & 0.3 & $0.47 \mid(0.194-1.074)$ & 0.07 & $0.707(0.380-1.329)$ & 0.3 \\
\hline $\begin{array}{l}\text { Hemoglobin } \\
<10.5 \mathrm{~g} / \mathrm{dL}\end{array}$ & I.I3I (0.456-2.959) & 0.8 & $1.229(0.573-2.533)$ & 0.6 & na & & na & \\
\hline $\mathrm{IPS} \geq 3$ & $1.286(0.52 \mathrm{I}-3.075)$ & 0.6 & $1.013(0.512-2.066)$ & 0.9 & $1.068(0.440-2.525)$ & 0.9 & $\mathrm{I} .297(0.659-2.65 \mathrm{I})$ & 0.5 \\
\hline $\begin{array}{l}\text { CR prior to } \\
\text { APHSCT }\end{array}$ & $0.435(0.068-1.555)$ & 0.2 & $0.618(0.23|-| .397)$ & 0.3 & $0.238(0.013-1.209)$ & 0.09 & $0.600(0.203-1.425)$ & 0.3 \\
\hline$A-L M R \geq I$ & $0.102(0.038-0.245)$ & $<0.0001$ & $0.162(0.082-0.305)$ & $<0.0001$ & $0.050(0.011-0.155)$ & $<0.0001$ & $0.106(0.046-0.220)$ & $<0.000$ I \\
\hline
\end{tabular}

Abbreviations: ALC-DX, absolute lymphocyte at diagnosis; A-LMR, autograft lymphocyte/monocyte ratio; APHSCT, autologous peripheral hematopoietic stem cell transplantation; Cl, confidence interval; CR, complete response; HR, hazard ratio; IPS, International Prognostic Score; LSS, lymphoma-specific survival; na, not applicable; OS, overall survival; PFS, progression-free survival; TTP, time to progression. 

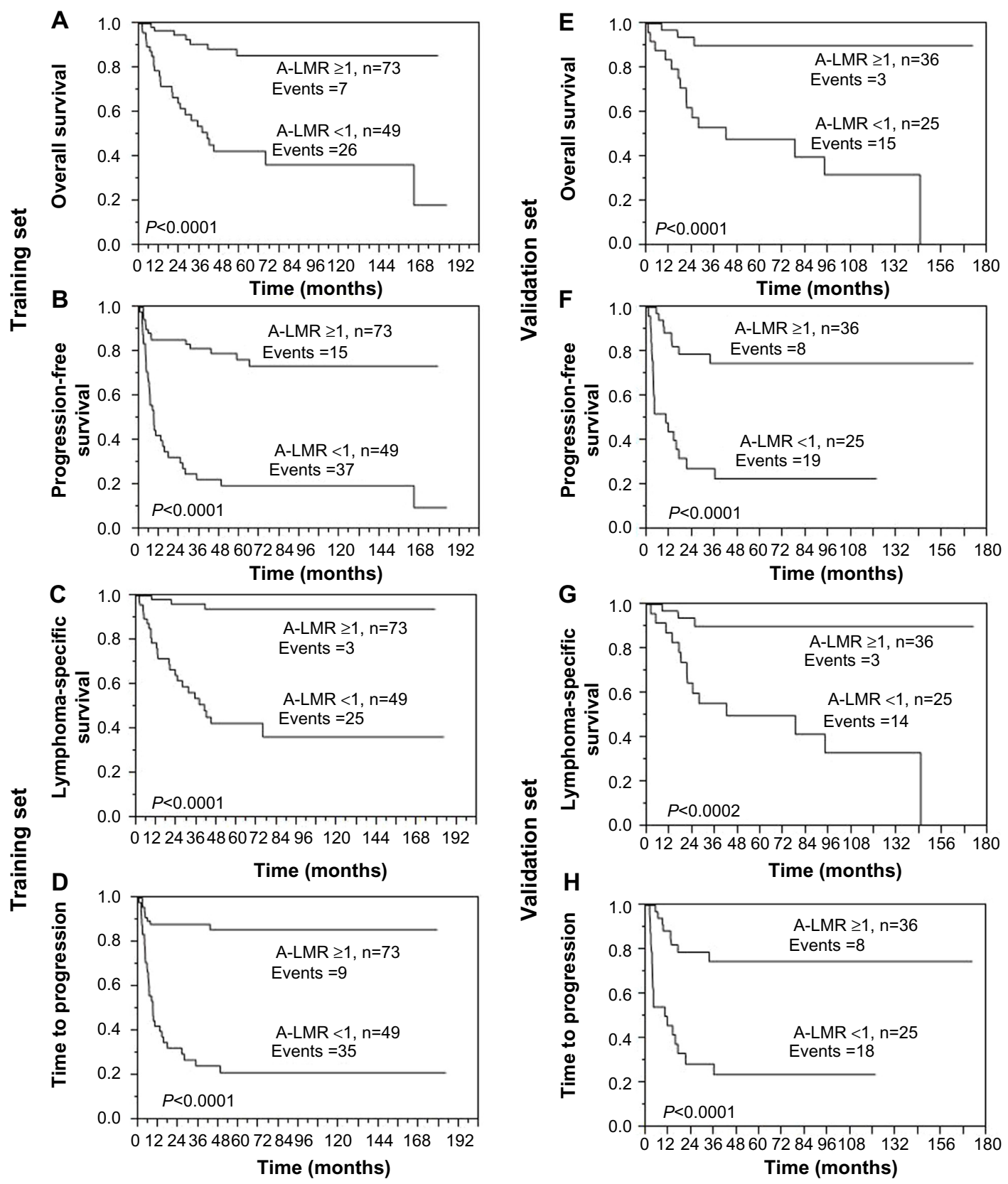

Figure I Survival outcomes based on A-LMR. (A) Overall survival, (B) progression-free survival, (C) lymphoma-specific survival, and (D) time to progression. Validation set. (E) Overall survival, (F) progression-free survival, (G) lymphoma-specific survival, and $(\mathbf{H})$ time to progression.

Abbreviation: A-LMR, autograft lymphocyte/monocyte ratio.

observed between the infused CD34 count and ALC-15, AMC-15, or LMR-15.

The A-LMR combines the biomarkers of A-ALC and A-AMC. We originally reported the prognostic significance of A-ALC $\geq 0.5 \times 10^{9}$ cells $/ \mathrm{kg}$ in lymphoma ${ }^{2}$ and multiple myeloma ${ }^{16}$ patients undergoing APHSCT. Independent groups have confirmed the prognostic significance of A-ALC. ${ }^{17}$ However, some patients still relapsed post-APHSCT despite being infused with A-ALC $\geq 0.5 \times 10^{9}$ cells $/ \mathrm{kg}$. Thus, we set out to investigate what other factors might counteract the survival benefits produced by A-ALC post-APHSCT. Recent studies have shown the immunosuppressive and tumor growth effects of MDSCs (ie, monocytes). ${ }^{3-9}$

Several mechanisms have been implicated with regard to how A-AMC might be associated with inferior survival post-APHSCT: production of immunosuppressive cytokines $;^{18}$ dysregulation of the CD8+T-specific peptidemajor histocompatibility complex; ${ }^{19}$ induction of regulatory T-cells; ${ }^{20}$ upregulation of the death receptor Fas, leading to T-cell apoptosis; ${ }^{20}$ and decreased natural killer 
cell function. In vitro studies have shown that removal of granulocytic-macrophages-CSF-mobilized or G-CSFmobilized CD14+ monocytes from the autograft increases natural killer cell function. ${ }^{21}$ This is an important finding, as we have previously published in a prospective study that natural killer cells are the main lymphocyte subset in ALC-15 affecting survival post-APHSCT. ${ }^{22}$

To minimize the inherent biases of a retrospective study, including selection bias and confounding factors, the following steps were taken. In regard to selection bias, we included only patients with the unifying diagnosis of $\mathrm{cHL}$ to obtain a homogeneous group. In addition, patients who received bone marrow harvest or a combination of bone marrow harvest/ peripheral blood stem cells were excluded. Only patients who received infused peripheral blood stem cells mobilized by G-CSF plus or minus plerixafor were included. Patients who had participated in stem cell transplant clinical trials were also excluded. Furthermore, patients were randomly divided into a training set and validation set to validate our findings. In regard to confounding factors, by multivariate analysis, A-LMR remained an independent prognostic factor when compared with currently known prognostic factors in cHL patients undergoing APHSCT.

The strengths of the study include long-term follow-up of a uniform group of patients with cHL treated consecutively at a single institution. This study expands on previous publications regarding A-ALC by highlighting the importance of the interaction between host immunity and MDSCs, using the simple biomarkers of A-ALC and A-AMC combined in the prognostic factor of A-LMR. Finally, the association between A-LMR and survival provides a rationale to develop clinical translational interventions to engineer immunocompetent autografts with a direct impact on immune recovery and survival post-APHSCT. In regard to the collection of MDSCs, G-CSF has been reported to be mobilized and upregulated in peripheral blood MDSCs, not only in patients undergoing APHSCT but also in normal donors for allogeneic stem cell transplantation. In allogeneic stem cell transplantation, the immunosuppressive effect of MDSCs could be exploited to treat graft-versus-host disease. Even the use of plerixafor has been associated with mobilization of high levels of monocytes in peripheral blood. ${ }^{23}$ Only $18 \%$ of patients received plerixafor in our cohort, so there were not enough events to perform meaningful statistical analysis to compare mobilization of monocytes between patients mobilized by G-CSF only versus patients mobilized by G-CSF and plerixafor. Therefore, more targeted stem cell mobilization agents to mobilize stem cells, immune effector cells, and minimize collection of MDSCs might be a new avenue for a more immunocompetent autograft. Another option to reduce the infusion of $\mathrm{CD} 14^{+}$immunosuppressive monocytes is to perform an autograft monocytic depletion using a CD $14^{+}$ column to remove MDSCs from the autograft product.

In conclusion, this study demonstrates A-LMR as a prognostic factor for clinical outcomes in $\mathrm{CHL}$ in addition to recently published A-LMR in DLBCL, suggesting A-LMR as a biomarker for engineering of immunocompetent autografts with a direct impact on clinical outcomes post-APHSCT in lymphomas.

\section{Author contributions}

All authors contributed toward data analyses, drafting, and revising the paper, and agree to be accountable for all aspects of the work.

\section{Disclosure}

The authors report no conflict of interest in this work.

\section{References}

1. Porrata LF, Inwards DJ, Ansell SM, et al. Infused autograft lymphocyte to monocyte ratio and survival in diffuse large B cell lymphoma. Biol Blood Marrow Transplant. 2014;20:1804-1812.

2. Porrata LF, Litzow MR, Inwards, DJ, et al. Infused peripheral blood autograft absolute lymphocyte count correlates with day 15 absolute lymphocyte count and clinical outcome after autologous peripheral hematopoietic stem cell transplantation in non-Hodgkin's lymphoma. Bone Marrow Transplant. 2004;33:291-298.

3. Lenz G, Wright G, Dave SS, et al. Stromal gene signatures in large B-cell lymphomas. N Engl J Med. 2008;358:2313-2323.

4. Steidl C, Lee T, Shah SP, et al. Tumor-associated macrophages and survival in classic Hodgkin's lymphoma $N$ Engl J Med. 2010;362: 875-885.

5. Gabrilovich DI, Nagaraj S. Myeloid-derived suppressor cells as regulators of the immune system. Nat Rev Immunol. 2009;9:162-172.

6. Lin Y, Gustafson, MP, Bulur PA, et al. Immunosuppressive CD14+ HLA-DR (low)/monocytes in B-cell non-Hodgkin lymphoma. Blood. 2011;117:872-881.

7. Ansell K, Porrata LF. Autograft monocytes: the bad humors of autologous peripheral blood hematopoietic stem cell transplantation. J Stem Cell Res Ther. 2013;S3:005.

8. Wilcox RA, Wada DA, Ziesmer SC, et al. Monocytes promote tumor cell survival in T-cell lymphoproliferative disorders and are impaired in their ability to differentiate into mature dendritic cells. Blood. 2009;114:2936-2944.

9. Shivakumar L, Ansell S. Targeting B-lymphocyte stimulator/B-cell activating factor and a proliferation-inducing ligand in hematologic malignancies. Clin Lymphoma Myeloma. 2006;7:106-108.

10. Hasenclever D, Diehl V. A prognostic score for advanced Hodgkin's disease. International Prognostic Factors Project on Advanced Hodgkin's Disease. N Engl J Med. 1998;339:1506-1514.

11. Cheson BD, Pfistner B, Juweid ME, et al. Revised response criteria for malignant lymphoma. J Clin Oncol. 2007;25:579-586.

12. Kaplan E, Meier P. Nonparametric estimation from incomplete observations. J Am Stat Assoc. 1958;53:457-481.

13. Cox R. Regression models and life-tables. J R Stat Soc Series B Stat Methodol. 1972;34:187-202. 
14. Tzankov A, Zlobec I, Went P, et al. Prognostic immunophenotypic biomarker studies in diffuse large B cell lymphoma with special emphasis on rational determination of cut-off scores. Leuk Lymphoma. 2010;51:199-212.

15. Porrata LF, Inwards DJ, Micallef IN, Ansell SM, Geyer SM, Markovic SN. Early lymphocyte recovery post-autologous haematopoietic stem cell transplantation is associated with better survival in Hodgkin's disease. Br J Haematol. 2002;117:629-633.

16. Porrata LF, Gertz MA, Geyer SM, et al. The dose of infused lymphocytes in the autograft directly correlates with clinical outcome after autologous peripheral blood hematopoietic stem cell transplantation in multiple myeloma. Leukemia. 2004;18:1085-1092.

17. Hiwase DK, Hiwase S, Bailey M, et al. Higher infused lymphocyte dose predicts higher lymphocyte recovery, which in turn, predicts superior overall survival following autologous hematopoietic stem cell transplantation for multiple myeloma. Biol Blood Marrow Transplant. 2008;14:116-124.

18. Singh RK, Ino K, Varney ML, et al. Immunoregulatory cytokines in bone marrow and peripheral blood stem cell products. Bone Marrow Transplant. 1999;23:53-62.
19. Nagaraj S, Gupta K, Pisareo V, et al. Altered recognition of antigen is a mechanism of CD8+ T cell tolerance in cancer. Nat Med. 2007;13: 828-835.

20. Talmadge JE. Hematopoietic stem cell graft manipulation as a mechanism of immunotherapy. Int Immunopharmacol. 2003;3:1121-1143.

21. Ageitos AG, Ino K, Ozerol L, et al. Restoration of T and NK cell function in GM-CSF mobilized stem cell products from breast cancer patients by monocyte depletion. Bone Marrow Transplant. 1997;20:117-173.

22. Porrata LF, Inwards DJ, Ansell SM, et al. Early lymphocyte recovery predicts superior survival after autologous stem cell transplantation in non-Hodgkin lymphoma: a prospective study. Biol Blood Marrow Transplant. 2008;14:807-816.

23. Varmavuo V, Mantymaa P, Kuittinene T, et al. Pre-emptive plerixafor injection increases blood neutrophil, lymphocyte, and monocyte counts in addition to CD34+ counts in patients with non-Hodgkin mobilizing poorly with chemotherapy plus G-CSF: Potential implications for apheresis and graft composition. Transfus Apher Sci. 2013;46: 257-262.

\section{Publish your work in this journal}

The Journal of Blood Medicine is an international, peer-reviewed, open access, online journal publishing laboratory, experimental and clinical aspects of all topics pertaining to blood based medicine including but not limited to: Transfusion Medicine; Blood collection, Donor issues, Transmittable diseases, and Blood banking logistics; Immunohematology; Artificial and alternative

\section{Dovepress}

blood based therapeutics; Hematology; Biotechnology/nanotechnology of blood related medicine; Legal aspects of blood medicine; Historical perspectives. The manuscript management system is completely online and includes a very quick and fair peer-review system. Visit http://www.dovepress.com/ testimonials.php to read real quotes from published authors.

Submit your manuscript here: http://www.dovepress.com/Journal-of-blood-medicine-journal 